\title{
METODOLOGIA DE CRIAÇÃO DE CÓDIGOS DE NOMENCLATURA DE VALOR ADUANEIRO E ESTATÍSTICA PARA INGREDIENTES ATIVOS UTILIZADOS NA PRODUÇÃO DE AGROTÓXICOS
}

\author{
DAYANI CRIS DE AQUINO * \\ RUTH M. HOFMANN ** \\ MARCELO FRANCISCO MELO *** \\ VICTOR PELAEZ \\ PETER REMBISCHEVSKI *****

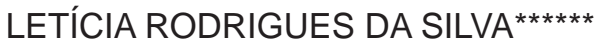

\begin{abstract}
Este artigo teve por objetivo descrever o processo de criação de Nomenclatura de Valor Aduaneiro e Estatística (NVE) dos agrotóxicos autorizados no Brasil, enquadrados no capítulo 29 da Nomenclatura Comum do Mercosul (NCM), intitulado "Produtos químicos orgânicos". O trabalho foi desenvolvido no intuito de (1) reduzir a falta de clareza decorrente da excessiva agregação da $\mathrm{NCM}$; (2) aumentar o controle legal de entrada e saída de ingredientes ativos (IA) do Brasil; e (3) criar bases de dados e de estatísticas para a implementação de sistema de inteligência regulatória para agrotóxicos. Foram criadas NVE para 345 IA empregados na fabricação de agrotóxicos e contemplados exclusivamente em 459 monografias elaboradas pela Agência Nacional de Vigilância Sanitária (ANVISA). Utilizou-se para a criação das NVE de IA voltados à produção de agrotóxicos, o mesmo atributo empregado para IA de produtos farmacêuticos. Foram utilizados, em ambos os casos, o número do Chemical Abstracts Service (CAS), seguido pela denominação da International Organization for Standardization (ISO), ou Denominação Comum Brasileira (DCB), aprovadas pelo Ministério da Saúde. A criação das NVE evidenciou o caráter incipiente do controle estatístico de entrada de agrotóxicos no Brasil mediante importação. Dos mais de 400 IA que originam produtos técnicos (PT) e formulados (PF) de agrotóxicos, apenas 19 tinham seu controle estatístico efetuado (descrição exata por meio de NCM de 8 dígitos), o que equivale a $4 \%$ do total de ingredientes ativos avaliados.
\end{abstract}

PALAVRAS-CHAVE: AGROTÓXICOS; NOMENCLATURA COMUM DO MERCOSUL (NCM); NOMENCLATURA DE VALOR ADUANEIRO E ESTATÍSTICA (NVE).

\footnotetext{
* Departamento de Economia, Universidade Federal do Paraná (UFPR) Curitiba, PR (e-mail: dayani. aquino@gmail.com).

** Departamento de Engenharia de Produção, UFPR, Curitiba, PR (e-mail: ruthofmann@gmail.com).

*** Bacharel em Ciências Econômicas, Universidade de Campinas, Campinas, SP (e-mail: marcelofmelo@ gmail.com).

**** Departamento de Economia, UFPR Curitiba, PR (e-mail: victor@ufpr.br).

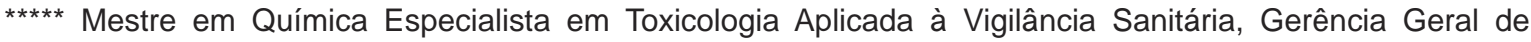
Toxicologia/Agência Nacional de Vigilância Sanitária, Brasília, DF (e-mail: peter.rembischevski@anvisa. gov.br).

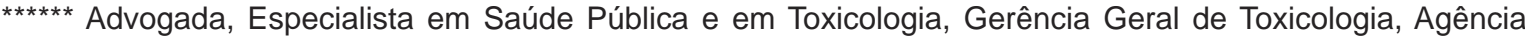
Nacional de Vigilância Sanitária, Brasília, DF (e-mail: leticia.silva@anvisa.gov.br).
} 


\section{INTRODUÇÃo}

A preocupação de entidades públicas e privadas com riscos sanitários tem incitado o desenvolvimento de arcabouço legal de controle e fiscalização da circulação de substâncias potencialmente nocivas à saúde e ao meio ambiente. As proibições da utilização de alguns agrotóxicos na União Europeia e até mesmo na China resultam do esforço de intensificação do controle sanitário da circulação de herbicidas, fungicidas e agrotóxicos em geral (DNA/PIC, 2008).

O acompanhamento do fluxo de comércio internacional de substâncias químicas constitui medida importante de controle de salubridade. Os mecanismos de acompanhamento de importações e exportações de mercadorias em geral, e de agrotóxicos em particular, têm sua eficiência e sua eficácia condicionadas à metodologia de coleta e sistematização dos dados e informações referentes ao fluxo de comércio internacional.

A Nomenclatura Comum do Mercosul (NCM) baseia-se no Sistema Harmonizado de Designação e de Codificação de Mercadorias (SH), método internacional de classificação de produtos. A NCM fundamenta as estatísticas geradas pelo Sistema Integrado de Comércio Exterior (SISCOMEX), inclusive no que tange às estatísticas de importação e exportação de agrotóxicos. Dentre os limites da NCM que mais afetam o acompanhamento brasileiro do fluxo de entrada e saída de ingredientes ativos (IA), utilizados na fabricação de agrotóxicos, destaca-se o elevado grau de agregação da NCM que inviabiliza a obtenção de dados estatísticos detalhados e compromete o controle legal das importações e exportações de IA essenciais para a indústria de agrotóxicos. A excessiva agregação das decrições dos códigos NCM impede a identificação individualizada dos IA, que muitas vezes são transacionados com a obscura e imprecisa denominação de "Outros" (por exemplo: "2920.10.90 - outros ésteres tiofosfóricos, seus sais, derivados halogenados etc." e "2920.90.29 - outros sulfitos de ésteres de ácidos inorgânicos"). Diante dessas limitações, a Instrução Normativa (IN) SRF no 80/96 instituiu a Nomenclatura de Valor Aduaneiro e Estatística (NVE), com o duplo propósito de (1) identificar, para fins de valoração aduaneira, as mercadorias submetidas a despacho aduaneiro de importação e (2) servir de fonte de aprimoramento das estatísticas de comércio exterior por meio de maior detalhamento do produto, com a inclusão de quatro dígitos adicionais nos códigos de comércio. A NVE foi criada a partir da Nomenclatura Comum do Mercosul (NCM), com atributos e especificações, identificados por dois caracteres alfabéticos e quatro numéricos, respectivamente. Os atributos servem para identificar as características, intrínsecas e extrínsecas, relevantes da mercadoria para a formação de seu preço. As especificações, por sua vez, servem para proporcionar o detalhamento de cada atributo, individualizando dessa forma a mercadoria importada (BRASIL, 2005).

Este artigo teve por objetivo descrever o processo de criação de NVE dos agrotóxicos autorizados no Brasil, enquadrados no capítulo 29 da NCM, intitulado "Produtos químicos orgânicos". O trabalho foi desenvolvido por iniciativa da Gerência Geral de Toxicologia da Agência Nacional de Vigilância Sanitária (ANVISA), em parceria com a Universidade Federal do Paraná (UFPR), no intuito de (1) reduzir a obscuridade decorrente da excessiva agregação da NCM; (2) aumentar o controle legal da entrada e saída de IA do Brasil; e (3) criar bases de dados e estatísticas para a implementação de sistema de inteligência regulatória para agrotóxicos. Foram criadas NVE para 345 ingredientes ativos (IA) empregados na fabricação de agrotóxicos e contemplados exclusivamente em 459 monografias elaboradas pela ANVISA (ANVISA, 2003). As NVE criadas passaram a ser incorporadas pela Receita Federal, resultando na publicação da Instrução Normativa no 953/09 - da Secretaria da Receita Federal, cuja entrada em vigor ocorreu em $1^{\circ}$ de agosto de 2009 (BRASIL, 2009).

\section{METODOLOGIA}

A Nomenclatura Comum do Mercosul (NCM) baseia-se no Sistema Harmonizado de 
Designação e de Codificação de Mercadorias (SH), método internacional de classificação de produtos, desenvolvido pela Organização Mundial de Alfândegas (OMA). A estrutura da NCM está descrita na Figura 1 e um exemplo dessa estrutura encontra-se no Quadro 1.

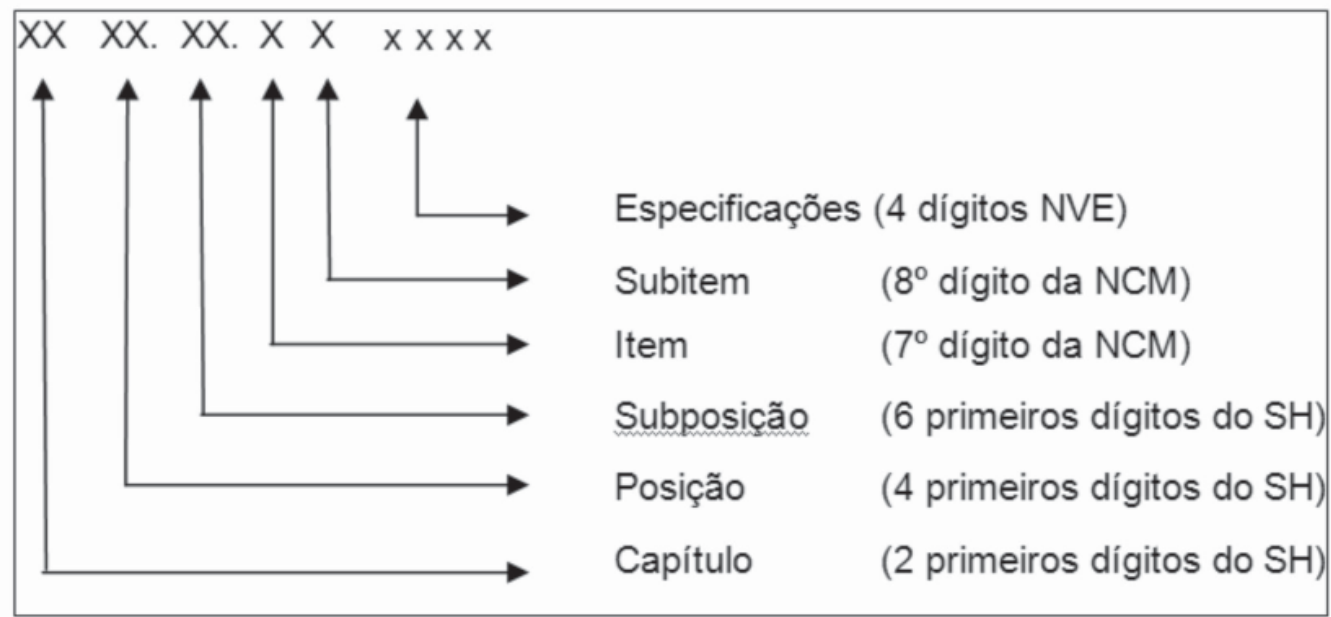

FIGURA 1 - ESTRUTURA DA NOMENCLATURA COMUM DO MERCOSUL SEGUIDA DAS ESPECIFICAÇÕES DA NVE Fonte: BRASIL, 2007.

\section{QUADRO 1 - EXEMPLO DE DESDOBRAMENTO DO CÓDIGO NCM: 2924.29.31 - CARBARIL}

\begin{tabular}{|c|c|c|}
\hline & & CARBARIL \\
\hline Seção & $\mathrm{VI}$ & Produtos das Indústrias Químicas ou das Indústrias Conexas \\
\hline Capítulo & 29 & Produtos químicos orgânicos \\
\hline Posição & 2924 & $\begin{array}{l}\text { Compostos de função carboxiamida; compostos de função amida } \\
\text { do ácido carbônico }\end{array}$ \\
\hline Subposição & 2924.29 & $\begin{array}{l}\text { Outras amidas (incluídos os carbamatos) cíclicas e seus derivados; } \\
\text { sais desses produtos }\end{array}$ \\
\hline Item & 2924.29 .3 & Carbamatos \\
\hline Subitem & 2924.29.31 & Carbaril \\
\hline
\end{tabular}

Fonte: BRASIL, 2007.a

Considerando que parte do objetivo do trabalho abrange a revisão dos critérios de classificação dos produtos agrotóxicos desagregados a seis dígitos no sistema Harmonizado e a oito dígitos da Nomenclatura Comum do Mercosul (NCM) procedeu-se à execução de duas atividades principais:

a) Acompanhamento e discussão dos critérios de desagregação a oito dígitos que pudessem disponibilizar informações mais detalhadas dos agrotóxicos fabricados e comercializados no Brasil; e

b) Acompanhamento e assessoramento do estabelecimento de Nomenclatura de Valor Estatístico (NVE), visando ao desagrupamento dos códigos relativos à importação e exportação de agrotóxicos de tal forma que se pudesse identificar cada um dos IA, individualmente. Essa desagregação possibilita, posteriormente, o acompanhamento preciso das importações e exportações de cada um dos IA. 
Os ingredientes ativos contemplados no processo de criação da NVE referem-se, predominantemente, ao capítulo 29 da NCM. Foram também abordados oito subitens do capítulo 28 , intitulado "Produtos químicos inorgânicos; compostos inorgânicos ou orgânicos de metais preciosos, de elementos radioativos, de metais das terras raras ou de isótopos".

\subsection{IDENTIFICAÇÃO DOS CÓDIGOS DE COMÉRCIO DOS INGREDIENTES ATIVOS}

A primeira etapa do trabalho de criação das NVE consistiu na identificação dos códigos NCM dos ingredientes ativos utilizados para fabricação de agrotóxicos, tendo como referência as definições encontradas nas monografias da ANVISA. O trabalho de identificação dos códigos foi dificultado por dois fatores principais, que incluíram a existência de:

a) divergências morfossintáticas entre as definições dos ingredientes ativos nas monografias e na NCM. Essas divergências complicaram a identificação daqueles IA que já tinham códigos NCM a oito dígitos e também daqueles que ainda não estavam desagregados na NCM. Muitas das descrições da NCM estavam grafadas em inglês, enquanto a descrição do ingrediente ativo na monografia estava em português (como, por exemplo, Thiram e Tiram). Outro obstáculo encontrado foi a grafia dos ingredientes ativos na NCM pelo nome químico e nas monografias pelo nome comum. Essas dificuldades inviabilizaram a utilização de softwares como o Excel para comparação das nomenclaturas, exigindo a análise dos 477 ingredientes ativos um a um;

b) incoerências no enquadramento químico das substâncias que já contavam com código NCM. Um exemplo de incoerência no enquadramento existente na NCM ocorreu com as benzoilureias, entre as quais o Triflumuron (2924.29.94) e o Diflubenzuron (2924.29.92) que figuravam em "Outras amidas (incluídos os carbamatos) cíclicas e seus derivados; sais destes produtos" (2924.29) em detrimento da correta classificação que seria juntamente com o Diuron (2924.21.20), dentre as "Ureínas e seus derivados; sais destes produtos" (2924.21). Dessa forma, julgou-se necessário enquadrar as benzoilureias restantes como Flufenoxurom, Hexaflumurom, Lufenurom, Novalurom e Teflubenzurom, sob a codificação 2924.29.99 (tais como seus congêneres Triflumuron e Diflubenzuron), quando o mais apropriado seria classificá-los em 2924.21.90, juntamente com o Diuron.

\subsection{CRITÉRIOS DE CRIAÇÃO DAS NVE}

O processo de desagregação das NCM em NVE foi norteado por um conjunto de critérios conceituais e metodológicos. Quando já havia NVE criada para determinado subitem dos capítulos NCM 28 e 29, a codificação da NVE já estabelecida foi respeitada e continuou-se a sequência a partir do último código, mantendo-se o código 9999 para "Outros". Por outro lado, quando não havia NVE criada para determinado subitem dos capítulos NCM 28 e 29 a codificação foi iniciada a partir de 0001.

Os critérios para a criação de NVE foram baseados fundamentalmente nas Notas Explicativas do Sistema Harmonizado e da Nomenclatura do SH. A determinação das posições das NCM não específicas (descritas genericamente como "Outros") para o enquadramento dos IA de agrotóxicos na nomenclatura da NCM seguiu os critérios estabelecidos na INS 157/02, Anexo Único - Notas Explicativas do Sistema Harmonizado (NESH) (BRASIL, 2002b). O trabalho baseou-se na descrição da NCM indicada na relação da Tarifa Externa Comum (TEC) mais recente (BRASIL, 2007a), atualizada pela Resolução CAMEX n 40, de 27/09/07 (BRASIL, 2007b). 
As NESH estabelecem o critério químico-estrutural para o adequado enquadramento das substâncias químicas em suas respectivas posições NCM descritas na TEC, sendo as regras de priorização de grupamentos químicos definidas em âmbito internacional (harmonizado). Os grupos químicos de importância toxicológica, ou relevantes para o modo de ação de determinado agrotóxico, são pouco representativos nessa priorização e na tarefa de enquadramento. Nesse sentido, temse, por exemplo, os agrotóxicos organofosforados clássicos (diclorvós, fenitrotion, monocrotofós ${ }^{1}$, metamidofós e clorpirifós) enquadrados respectivamente nos subitens NCM 2919, 2920, 2924, 2930 e 2933. Esse foi o procedimento seguido ao longo de todo o trabalho para o enquadramento dos IA de agrotóxicos não descritos com subitens na NCM.

O esforço de compatibilização incluiu a comparação entre os grupos químicos definidos nas monografias e o enquadramento dos ingredientes ativos na NCM, tal como indicado no Quadro 2.

\section{QUADRO 2 - COMPARAÇÃO ENTRE OS GRUPOS QUÍMICOS DEFINIDOS NAS MONOGRAFIAS ANVISA E O ENQUADRAMENTO NA NCM}

\begin{tabular}{|c|c|c|c|}
\hline IA & $\begin{array}{l}\text { Grupo químico } \\
\text { monografia }\end{array}$ & Código NCM & Descrição na NCM \\
\hline Abamectina & Avermectina & 2932 & $\begin{array}{l}\text { Compostos heterocíclicos } \\
\text { exclusivamente de } \\
\text { heteroátomo(s) de oxigênio }\end{array}$ \\
\hline $\begin{array}{l}\text { Captana } \\
\text { Carbaril }\end{array}$ & $\begin{array}{l}\text { Dicarboximida } \\
\text { Carbamato* }\end{array}$ & $\begin{array}{c}2930 \\
2924.1\end{array}$ & $\begin{array}{l}\text { Tiocompostos orgânicos } \\
\text { Amidas (incluídos os } \\
\text { carbamatos) acíclicas e } \\
\text { seus derivados; sais destes } \\
\text { produtos }\end{array}$ \\
\hline Carbofurano & Carbamato** & 2932 & $\begin{array}{l}\text { Compostos heterocíclicos } \\
\text { exclusivamente de } \\
\text { heteroátomo(s) de oxigênio }\end{array}$ \\
\hline Clorotalonil & Isoftalonitrila & 2926 & Compostos de função nitrila \\
\hline Clorpirifós & Organofosforado & 2933 & $\begin{array}{l}\text { Compostos heterocíclicos } \\
\text { exclusivamente de } \\
\text { heteroátomo(s) de nitrogênio }\end{array}$ \\
\hline Deltametrina & Piretroide & 2926 & Compostos de função nitrila \\
\hline Diclorvós & Organofosforado & 2919 & $\begin{array}{l}\text { Ésteres fosfóricos e } \\
\text { seus sais, incluídos os } \\
\text { lactofosfatos }\end{array}$ \\
\hline Dicofol & Organoclorado & 2905 & $\begin{array}{c}\text { Alcoóis cíclicos e seus deri- } \\
\text { vados }\end{array}$ \\
\hline Endossulfam & $\begin{array}{l}\text { Clorociclodieno } \\
\text { (Organoclorado) }\end{array}$ & 2920 & $\begin{array}{l}\text { Ésteres dos outros ácidos } \\
\text { inorgânicos de não metais } \\
\text { e seus sais; seus derivados } \\
\text { halogenados, sulfonados, } \\
\text { nitrados ou nitrosados }\end{array}$ \\
\hline
\end{tabular}

continua...

1 Ingrediente ativo proibido de comercialização no Brasil, mas que consta na NCM. 


\begin{tabular}{|c|c|c|c|}
\hline Endossulfam & $\begin{array}{l}\text { Clorociclodieno } \\
\text { (Organoclorado) }\end{array}$ & 2920 & $\begin{array}{l}\text { Ésteres dos outros } \\
\text { ácidos inorgânicos } \\
\text { de não-metais e seus } \\
\text { sais; seus derivados } \\
\text { halogenados, } \\
\text { sulfonados, nitrados } \\
\text { ou nitrosados }\end{array}$ \\
\hline Fenitrotiona & Organofosforado & 2920 & $\begin{array}{l}\text { Ésteres dos outros } \\
\text { ácidos inorgânicos } \\
\text { de não-metais e seus } \\
\text { sais; seus derivados } \\
\text { halogenados, } \\
\text { sulfonados, nitrados } \\
\text { ou nitrosados }\end{array}$ \\
\hline Fenvalerato & Piretroide & 2926 & $\begin{array}{l}\text { Compostos de função } \\
\text { nitrila }\end{array}$ \\
\hline Glifosato & Glicina substituída & 2931.00 .90 & $\begin{array}{l}\text { Outros compostos } \\
\text { organo-inorgânicos }\end{array}$ \\
\hline Glufosinato de amônio & $\begin{array}{l}\text { Homoalanina } \\
\text { substituída }\end{array}$ & 2931.00 .90 & $\begin{array}{l}\text { Outros compostos } \\
\text { organo-inorgânicos }\end{array}$ \\
\hline Metamidofós & Organofosforado & 2930 & $\begin{array}{l}\text { Tiocompostos } \\
\text { orgânicos }\end{array}$ \\
\hline Metomil & Carbamato*** & 2930 & $\begin{array}{l}\text { Tiocompostos } \\
\text { orgânicos }\end{array}$ \\
\hline Monocrotofós & Organofosforado & 2924.1 & $\begin{array}{l}\text { Amidas (incluídos os } \\
\text { carbamatos) acíclicas } \\
\text { e seus derivados; sais } \\
\text { destes produtos }\end{array}$ \\
\hline Paraquat & Bipiridílio & 2933 & $\begin{array}{l}\text { Compostos } \\
\text { heterocíclicos } \\
\text { exclusivamente de } \\
\text { heteroátomo(s) de } \\
\text { nitrogênio }\end{array}$ \\
\hline Picloram & $\begin{array}{c}\text { Ácido } \\
\text { piridinocarboxílico }\end{array}$ & 2933 & $\begin{array}{l}\text { Compostos } \\
\text { heterocíclicos } \\
\text { exclusivamente de } \\
\text { heteroátomo(s) de } \\
\text { nitrogênio }\end{array}$ \\
\hline Tiofanato de metila & Benzimidazol & 2930 & $\begin{array}{l}\text { Tiocompostos } \\
\text { orgânicos }\end{array}$ \\
\hline Tiram & Dimetilditiocarbamato & 2930 & $\begin{array}{l}\text { Tiocompostos } \\
\text { orgânicos }\end{array}$ \\
\hline
\end{tabular}

*Metilcarbamato de naftila. ** Metilcarbamato de benzofuranila. *** Metilcarbamato de oxima.

A comparação da classificação de alguns agrotóxicos quanto ao seu grupo químico (Quadro 2) revela que nem sempre há convergência entre os critérios internacionais nos quais as monografias da ANVISA se basearam (WOOD, 2003) e os critérios internacionalmente adotados para efeito de classificação na NCM. A diferença deve-se à adoção de critérios distintos de priorização dos grupamentos químicos da molécula. Para a determinação de grupos químicos de agrotóxicos, os grupamentos considerados prioritariamente foram aqueles responsáveis pelo modo de ação sobre o organismo alvo ${ }^{2}$, enquanto as regras de priorização de grupamentos químicos definidas

2 Para efeito de classificação de comércio, organizações como as Nações Unidas agrupam as substâncias de acordo com seu uso, codificando-as com descrições como herbicidas, fungicidas, inseticidas, etc. 
na NESH baseiam-se estritamente em critérios químico-estruturais. Pode-se notar no Quadro 2, por exemplo, que a posição NCM 2930, referente a tiocompostos orgânicos, reúne IA dos grupos químicos carbamato, benzimidazol, dimetiltiocarbamato e dicarboximida na monografia ANVISA. Da mesma forma, IA do mesmo grupo químico (a exemplo dos organofosforados) pode se enquadrar em diferentes posições nas descrições da NCM. Como a classificação adotada pela NCM não pode ser alterada, procurou-se seguir a lógica definida pelas características estruturais dos grupamentos químicos. Isto significa que dentro de determinada estrutura química, caracterizada por código NCM, poderá haver mais de um IA com distintas DESCRIÇÕES baseadas em CAS-ISO, levando à necessidade de se criar mais de uma NVE por código NCM.

Utilizou-se para a criação das NVE de IA voltados à produção de agrotóxicos o mesmo atributo empregado para ingredientes ativos de produtos farmacêuticos. Foram utilizados, em ambos os casos, o número do Chemical Abstracts Service (CAS), seguido pela denominação da International Organization for Standardization (ISO) ou Denominação Comum Brasileira (DCB), aprovadas pelo Ministério da Saúde.

\section{RESULTADOS E DISCUSSÃO}

As monografias apresentadas pela ANVISA resultam da avaliação e da reavaliação toxicológica ${ }^{3}$ dos ingredientes ativos destinados ao uso agrícola, domissanitário, não agrícola e preservantes de madeira. Cada monografia inclui os nomes comum e químico, a classe de uso, a classificação toxicológica e as culturas para as quais os ingredientes ativos encontram-se autorizados, com seus respectivos limites máximos de resíduo. As monografias e, portanto, os ingredientes ativos avaliados pela ANVISA somavam 477 por ocasião da criação das NVE. Foram analisados 459 ingredientes ativos, desconsiderando-se 18 deles por se caracterizarem como misturas de IA ou já estarem de alguma forma contemplados em outros enquadramentos. ${ }^{4} \mathrm{O}$ Quadro 3 apresenta a síntese dos resultados obtidos com o processo de desagregação de NCM em NVE.

\section{QUADRO 3 - RESULTADO DA ANÁLISE DAS MONOGRAFIAS PARA CRIAÇÃO DE NVE}

\begin{tabular}{|lcc|}
\hline \multicolumn{1}{|c}{ RESULTADO DA AVALIAÇÃo } & Quantidade & $\begin{array}{c}\text { Percentual em } \\
\text { relação ao total } \\
\text { analisado }\end{array}$ \\
\hline $\begin{array}{l}\text { Total de IA analisados } \\
\text { Códigos NCM a 8 dígitos já correlacionados com as } \\
\text { monografias } \\
\text { Códigos NCM a 8 dígitos que tiveram NVE criadas }\end{array}$ & 459 & $100 \%$ \\
$\begin{array}{l}\text { Total de NVE criadas (excluindo NVE 9999, que correspondem } \\
\text { a "outros" dentro da NVE) }\end{array}$ & 95 & $21 \%$ \\
$\begin{array}{l}\text { NVE de ingredientes ativos do capítulo 29 já criadas pela } \\
\text { Receita } \\
\text { Códigos com divergências morfossintáticas (NCM x }\end{array}$ & 345 & $22 \%$ \\
Monografias) \\
Códigos NCM a 8 dígitos com incoerências de enquadramento
\end{tabular}

Nota: foram criadas, em média, 3,45 NVE por NCM.

3 O artigo 19 do Decreto 4.074/02 determina que os órgãos federais de agricultura, saúde e meio ambiente devem avaliar as informações apontadas por organizações internacionais responsáveis pela saúde, alimentação ou meio ambiente, quando essas alertarem para riscos ou desaconselharem o uso de agrotóxicos ou de qualquer substância a eles relacionados, devendo adotar providências imediatas, sob pena de responsabilidade (ANVISA, 2002a).

4 Acetamiprido, Bentazona, Buprofenzina, Clorfenapir, Compostos à Base de Cobre, Dicamba, Geraniol, Metaldeído, Orizalina, Pimetroniza, Protioconazol, Tembotrione, Terra diatomácea, Tiazopir, Grandlure, Macex, Óleo Mineral, Óleo Vegetal. 
Do total de ingredientes ativos analisados, 95 (21\%) já tinham código NCM a oito dígitos, mantendo-se correlação aceitável entre o nome do ingrediente ativo e a descrição da mercadoria codificada na NCM; 19 (4\%) já contavam com NVE criadas pela Receita; e 345 (75\% das monografias analisadas) foram enquadradas em 100 códigos NCM com a criação das respectivas NVE, gerando em média 3,45 NVE por código.

A estrutura de criação das NVE resultou na desagregação expressa no Quadro 4, que contém exemplos da criação de NVE.

QUADRO 4 - ESTRUTURA DE DESAGREGAÇÃO DE NCM EM NVE DE IA

\begin{tabular}{|c|c|c|c|c|c|}
\hline Categoria & NCM & Descrição NCM & NVE & CAS - ISO & Descrição \\
\hline Capítulo & 28 & $\begin{array}{l}\text { Produtos químicos inorgânicos; } \\
\text { compostos inorgânicos ou } \\
\text { orgânicos de metais preciosos, de } \\
\text { elementos radioativos, de metais } \\
\text { das terras raras ou de isótopos }\end{array}$ & & & \\
\hline Subposição 2 & 2810.00 & Óxidos de boro; ácidos bóricos & & & \\
\hline Subitem & 2810.00 .90 & $\begin{array}{l}\text { Óxidos de boro e outros ácidos } \\
\text { bóricos }\end{array}$ & & & \\
\hline \multicolumn{6}{|l|}{$\begin{array}{l}\text { Atributos e } \\
\text { Especificações } \\
\text { de Nível 'U' }\end{array}$} \\
\hline \multicolumn{6}{|l|}{$\begin{array}{l}\text { Atributo AA } \\
\text { CAS/ISO }\end{array}$} \\
\hline & & & Especificações & & \\
\hline & & & 0001 & $10043-35-3$ & Ácido Bórico \\
\hline & & & 0002 & $1303-96-4$ & Bórax \\
\hline & & & 0003 & $12280-03-4$ & $\begin{array}{l}\text { Octaborato } \\
\text { dissódio tetrahi- } \\
\text { dratado }\end{array}$ \\
\hline & & & 9999 & Outros & \\
\hline Capítulo & 29 & Produtos químicos orgânicos & & & \\
\hline Posição & 2905 & $\begin{array}{l}\text { Álcoois acíclicos e seus derivados } \\
\text { halogenados, sulfonados, nitrados } \\
\text { ou nitrosados }\end{array}$ & & & \\
\hline Subposição 2 & 2905.29 & $\begin{array}{l}\text { Outros monoálcoois não saturados } \\
\text { não contemplados de } 2905.22 \text { a } \\
2905.22 .90\end{array}$ & & & \\
\hline Subitem & 2905.29 .90 & $\begin{array}{l}\text { Outros monoálcoois não saturados } \\
\text { não contemplados em 2905.29.10 }\end{array}$ & & & \\
\hline \multicolumn{6}{|l|}{$\begin{array}{l}\text { Atributos e } \\
\text { Especificações de } \\
\text { Nível 'U' }\end{array}$} \\
\hline \multicolumn{6}{|l|}{$\begin{array}{l}\text { Atributo AA CAS/ } \\
\text { ISO }\end{array}$} \\
\hline & & & Especificações & & \\
\hline & & & 0001 & $33956-49-9$ & Codlelure \\
\hline & & & 0002 & $42513-42-8$ & (E)-8-dodecenol \\
\hline & & & 0003 & $40642-40-8$ & (Z)-8-dodecenol \\
\hline & & & 0004 & $61301-56-2$ & $\begin{array}{l}\text { E -11-hexade- } \\
\text { cenol }\end{array}$ \\
\hline
\end{tabular}

continua... 


\begin{tabular}{|c|c|c|c|c|c|}
\hline Categoria & NCM & Descrição NCM & NVE & CAS - ISO & Descrição \\
\hline & & & 0005 & $\begin{array}{l}153665- \\
39-5\end{array}$ & Rincoforol \\
\hline & & & 9999 & Outros & \\
\hline Capítulo & 29 & & & & \\
\hline Posição & 2915 & $\begin{array}{l}\text { Ácidos monocarboxílicos } \\
\text { acíclicos saturados e seus } \\
\text { anidridos, halogenetos, peróxidos } \\
\text { e perácidos; seus derivados } \\
\text { halogenados, sulfonados, nitrados } \\
\text { ou nitrosados }\end{array}$ & & & \\
\hline Subposição 2 & 2915.39 & Outros ésteres do ácido acético & & & \\
\hline $\begin{array}{l}\text { Item } \\
\text { Subitem }\end{array}$ & $\begin{array}{l}2915.39 .9 \\
2915.39 .99\end{array}$ & $\begin{array}{l}\text { Outros ésteres do ácido acético } \\
\text { não contemplados de } 2915.39 .10 \text { a } \\
2915.39 .63 \\
\text { Outros ésteres do ácido acético } \\
\text { não contemplados de } 2915.39 .91 \text { a } \\
2915.39 .94\end{array}$ & & & \\
\hline \multicolumn{6}{|l|}{$\begin{array}{l}\text { Atributos e } \\
\text { Especificações de } \\
\text { Nível 'U' }\end{array}$} \\
\hline \multicolumn{6}{|l|}{ Atributo AA CAS } \\
\hline & & & Especificações & & \\
\hline & & & 0001 & $\begin{array}{l}163041- \\
94-9\end{array}$ & $\begin{array}{l}\text { Acetato de } \\
(E, Z, Z)-3,8,11- \\
\text { tetradecatrienila }\end{array}$ \\
\hline & & & 0002 & $30507-70-1$ & $\begin{array}{l}\text { Acetato de } \\
(Z, E)-9,12- \\
\text { tetradecadienila }\end{array}$ \\
\hline & & & 0003 & $\begin{array}{l}163041- \\
87-0\end{array}$ & $\begin{array}{l}\text { Acetato de } \\
(\mathrm{E}, \mathrm{Z})-3,8- \\
\text { tetradecadienila }\end{array}$ \\
\hline & & & 0004 & $34010-20-3$ & $\begin{array}{l}\text { Acetato de (Z)- } \\
\text { 9-hexadecenila }\end{array}$ \\
\hline & & & 0005 & $\begin{array}{l}174659- \\
87-1\end{array}$ & $\begin{array}{l}\text { Acetato de } \\
(E, Z)-3,5- \\
\text { dodecadienila }\end{array}$ \\
\hline & & & 0006 & $38363-29-0$ & $\begin{array}{l}\text { Acetato de (E)- } \\
\text { 8-dodecenila }\end{array}$ \\
\hline & & & 0007 & $28079-04-1$ & $\begin{array}{l}\text { Acetato de (Z)- } \\
\text { 8-dodecenila }\end{array}$ \\
\hline & & & 0008 & $34010-21-4$ & $\begin{array}{l}\text { Acetato de (Z)- } \\
\text { 11-hexadecenila }\end{array}$ \\
\hline & & & 0009 & $14959-86-5$ & $\begin{array}{l}\text { Acetato de (Z)- } \\
\text { 7-dodecenila }\end{array}$ \\
\hline & & & 0010 & $16725-53-4$ & $\begin{array}{l}\text { Acetato de (Z)- } \\
\text { 9-tetradecenila }\end{array}$ \\
\hline & & & 0011 & $16974-11-1$ & $\begin{array}{l}\text { Acetato de (Z)- } \\
\text { 9-dodecenila }\end{array}$ \\
\hline & & & 0012 & $61810-56-8$ & $\begin{array}{l}\text { Acetato de } \\
(E, Z, Z)-4,7,10- \\
\text { tridecatrienila }\end{array}$ \\
\hline & & & 0013 & $57981-60-9$ & $\begin{array}{l}\text { Acetato de } \\
\text { (E,Z)-4,7- } \\
\text { tridecadienila }\end{array}$ \\
\hline & & & 0014 & $16676-96-3$ & $\begin{array}{l}\text { Acetato de (Z)- } \\
\text { 5-dodecenila }\end{array}$ \\
\hline
\end{tabular}

continua... 
Continuação

\begin{tabular}{|c|c|c|c|c|c|}
\hline Categoria & NCM & Descrição NCM & NVE & CAS - ISO & Descrição \\
\hline & & & 0015 & 50933-33-0 & Gossiplure \\
\hline & & & 0016 & $3572-06-3$ & Cuelure \\
\hline & & & 9999 & Outros & \\
\hline Capítulo & 29 & Produtos químicos orgânicos & & & \\
\hline Posição & 2916 & $\begin{array}{l}\text { Ácidos monocarboxílicos } \\
\text { acíclicos não saturados e ácidos } \\
\text { monocarboxílicos cíclicos, seus } \\
\text { anidridos, halogenetos, peróxidos e } \\
\text { perácidos e seus derivados }\end{array}$ & & & \\
\hline Subposição 2 & 2916.20 & $\begin{array}{l}\text { Ácidos monocarboxílicos } \\
\text { ciclânicos, ciclênicos ou } \\
\text { cicloterpênicos, seus anidridos, } \\
\text { halogenetos, peróxidos, perácidos } \\
\text { e seus derivados }\end{array}$ & & & \\
\hline Item & 2916.20 .1 & $\begin{array}{l}\text { Derivados do ácido } \\
\text { ciclopropanocarboxílico }\end{array}$ & & & \\
\hline Subitem & 2916.20.19 & $\begin{array}{l}\text { Outros derivados do ácido } \\
\text { ciclopropanocarboxilico }\end{array}$ & & & \\
\hline \multicolumn{6}{|l|}{$\begin{array}{l}\text { Atributos e } \\
\text { Especificações } \\
\text { de Nível 'U' }\end{array}$} \\
\hline \multicolumn{6}{|l|}{$\begin{array}{l}\text { Atributo AA CAS/ } \\
\text { ISO }\end{array}$} \\
\hline & & & Especificações & & \\
\hline & & & 0001 & $54406-48-3$ & Empentrina \\
\hline & & & 0002 & $28434-00-6$ & Esbiol \\
\hline & & & 0003 & $66230-04-4$ & Esfenvalerato \\
\hline & & & 0004 & $28434-00-6$ & Esbiotrim \\
\hline & & & 0005 & $26002-80-2$ & Fenotrina \\
\hline & & & 0006 & $72963-72-5$ & Imiprotrim \\
\hline & & & 0007 & $\begin{array}{l}240494- \\
70-6\end{array}$ & Metoflutrina \\
\hline & & & 0008 & $23031-36-9$ & Praletrina \\
\hline & & & 0009 & $26002-80-2$ & Sumitrina \\
\hline & & & 0010 & $\begin{array}{l}118712- \\
89-3\end{array}$ & Transflutrina \\
\hline & & & 0011 & $8003-34-7$ & Piretrinas \\
\hline & & & 9999 & Outros & \\
\hline
\end{tabular}

Pode-se observar que, em casos como o do código NCM 2905.29.90 - "Outros monoálcoois não saturados não classificados em 2905.29.10" - foram necessárias cinco NVE para contemplar IA com descrições suficientemente precisas e individualizadas. Tal ilustração é emblemática na 
caracterização do caso mais recorrente: sob a denominação genérica e demasiadamente abrangente de "outros", muitos códigos NCM se revelaram insuficientes para garantir o acompanhamento adequado do fluxo de comércio internacional de agrotóxicos. A criação das NVE possibilita, dessa forma, ampliar o controle de entrada e saída de agrotóxicos no Brasil.

\section{CONCLUSÃO}

O controle estatístico da entrada de agrotóxicos no Brasil mediante importação revelase bastante incipiente, dado que dos mais de 400 IA que originam produtos agrotóxicos, apenas 19 tinham seu controle estatístico efetuado por meio de descrição exata de NCM a 8 dígitos. Isto equivale a $4 \%$ do total de IA. Os demais se encontravam enquadrados na categoria de "outros" da NCM, isto é, sem a possibilidade de identificação e controle fiscal específicos por meio de codificação de oito dígitos, ou não apresentavam denominações que permitissem seu reconhecimento, estando contemplados em descrições demasiadamente genéricas e abrangentes. Diante dessa limitação, foi necessária a criação de 345 NVE, o que corresponde a $75 \%$ do toal de monografias analisadas.

A complexidade do processo de criação das NVE se expressou, sobretudo, em duas dificuldades essenciais. Por um lado, as divergências morfossintáticas entre as definições dos IA nas monografias e na NCM impediram a identificação imediata de correspondências importantes. Por outro lado, as incoerências no enquadramento químico das substâncias, que já tinham código NCM, dificultou a composição de sequencia lógica de classificação. Não obstante, procurou-se, ao longo de todo o processo, respeitar a lógica de classificação da NCM, seguindo a mesma metodologia empregada na criação de NVE para fármacos: o número CAS seguido pela denominação ISO ou DCB, tal como aprovadas pelo Ministério da Saúde.

O trabalho de desagregação de NCM em NVE forneceu subsídios à Receita Federal para que esse controle possa ser efetuado para os Produtos Técnicos de agrotóxicos que sejam importados pelo Brasil, a partir da identificação química e devido enquadramento de cada IA com sua respectiva NCM de 8 dígitos. Vale finalmente ressaltar a necessidade de estudo mais amplo que pudesse revisar as inconsistências e incoerências das classificações dos IA, adotadas pela NCM, a exemplo do caso das benzoilureias, entre as quais o Triflumuron (2924.29.94) e o Diflubenzuron (2924.29.92), que figuravam em "Outras amidas (incluídos os carbamatos) cíclicas e seus derivados; sais desses produtos" (2924.29), quando sua correta classificação seria juntamente com Diuron (2924.21.20), dentre as "Ureínas e seus derivados; sais desses produtos" (2924.21). Tal revisão teria, portanto, o intuito de estabelecer critérios mais específicos e coerentes com os mecanismos de ação das substâncias agrotóxicas. Isto poderia facilitar o controle do comércio de agrotóxicos pelas autoridades reguladoras.

\section{ABSTRACT \\ METHODOLOGY FOR CREATION OF NOMENCLATURE OF CUSTOM VALUE AND STATISTICS CODES FOR ACTIVE INGREDIENTS OF PESTICIDES}

This paper analyses the process of creation of Nomenclature of the Statistics and Customs Value (NVE, acronym in Portuguese) of pesticides permitted in Brazil within Chapter 29 of the Mercosur Common Nomenclature (NCM, acronym in Portuguese), entitled "Organic chemicals products". The study was conducted in order to (1) reduce the obscurity arising from the excessive aggregation of the NCM, (2) increasing the legal control of incoming and outgoing active ingredients ( $\mathrm{Al}$ ) in the country, and (3) create databases and statistics for the implementation of a regulatory system for pesticides intelligence. NVE were created for 345 active ingredients (AIs) used in the manufacture of pesticides and exclusively covered in 459 monographs prepared by ANVISA (Agência Nacional de Vigilância Sanitária). The attribute used to create the NVE of Al focused on the production of pesticides was also used in creating Als for pharmaceuticals. It was used in both cases the CAS (Chemical Abstracts Service) followed by the designation ISO (International Organization for Standardization) or DCB (Brazilian Common Name) approved by the Ministry of Health said NVE. The creation of the incipient nature of statistical input of 
pesticides in the country through imports. Of the more than 400 products originating Al technicians (PT) and formulated (PF) of pesticides, only 19 had done its statistical control (through an accurate description of NCM 8 digits), which equals $4 \%$ of total assessed $\mathrm{Al}$.

KEY-WORDS: PESTICIDES; MERCOSUR COMMON NOMENCLATURE (NCM); NOMENCLATURE AND STATISTICS OF VALUATION (NVE).

\section{REFERÊNCIAS}

1 ANVISA. Agência Nacional de Vigilância Sanitária. Decreto n $^{\circ}$ 4.074, de 4 de janeiro de 2002a. Brasília/DF, 2002a. Disponível em: <http://www.planalto.gov.br/ccivil_03/decreto/2002/d4074.htm> Acesso em: 30 de agosto de 2010.

2 ANVISA. Agência Nacional de Vigilância Sanitária. Resolução - RE n 165, de 29 de agosto de 2003. Relação das monografias dos ingredientes ativos, domissanitários e preservantes de madeira, cujo emprego encontra-se autorizado. Brasília/DF, 2003. Disponível em: <http://portal.anvisa.gov.br/wps/content/Anvisa+Portal/Anvisa/Inicio/ Agrotoxicos+e+Toxicologia>. Acesso em: 30 de agosto de 2010.

3 BRASIL. Ministério do Desenvolvimento, Indústria e Comércio. Tarifa Externa Comum - TEC. Brasília/DF, 2007a. Disponível em: <http://www.desenvolvimento.gov.br/portalmdic/sitio/interna/interna.php?area=5\&menu=1848> Acesso em: 29 de agosto de 2007 .

4 BRASIL. Ministério do Desenvolvimento, Indústria e Comércio. Câmara de Comércio Exterior (MDIC/CAMEX). Resolução $n^{\circ}$ 40, de 27 de setembro de 2007. Determina as alíquotas do imposto de importação que compõem a tarifa externa comum (TEC). Brasília/DF, 2007b. Disponível em: <http://www.mdic.gov.br/arquivo/legislacao/rescamex/2007/ rescamex040-07.pdf> Acesso em: 30 de novembro de 2007.

5 BRASIL. Ministério da Fazenda. Instrução Normativa SRF $\mathbf{n}^{\circ}$ 157, de 10 de maio de 2002b. Notas explicativas do sistema de harmonização de designação e de codificação de mercadorias (NESH). Brasília/DF, 2002. Disponível em: <http://www.receita.fazenda.gov.br/Legislacao/ins/2002/in1572002.htm> Acesso em: 29 de agosto de 2007.

6 BRASIL. Ministério da Fazenda. Receita Federal. Estatísticas de importação por NVE: nota explicativa. Brasília/DF, 2005. Disponível em: <http://www.receita.fazenda.gov.br/Publico/Aduana/Estatisticas/NotaExplicativa.doc>. Acesso em: 20 de dezembro de 2009.

7 BRASIL. Ministério da Fazenda. Instrução Normativa n 953/09 SRB de 03 de julho de 2009. Altera o anexo da IN SRF 80/1996. Brasília/DF, 2009. Disponível em: <http://www.receita.fazenda.gov.br/legislacao/ins/2009/in9532009.htm> Acesso em: 30 de agosto de 2010.

8 Designated National Authority for Pesticide Ministry of Agriculture (DNA/PIC). Phase out of $\mathbf{5}$ organophosphate pesticides with high toxicity in China. Rotterdam Convention/Conference of the Parties 4. Rome, 2008. p. 27-31.

9 WOOD, A. Compendium of pesticides common names. 2003. Disponível em: <http://www.hclrss.demon.co.uk/index. html>. Acesso em: 17 de dezembro de 2007. 